11 Sloggett A, Joshi H. Higher mortality in deprived areas: community or personal disadvantage? BMJ 1994;309:1470-4.

12 Office of Population Censuses and Surveys. Standard occupational classification. London: HMSO, 1991.

13 Stata Corporation. Stata statistical software release 5.0. College Station, TX: StataCorp, 1997.

14 Wilson R, Walker A, Dueker DK, Pitts-Crick R. Risk factors for rate of progression of glaucomatous visual field loss. Arch Ophthalmol 1982;100:737.

15 Mikelburg FS, Schulzer M, Drance SM, Lau W. The rate of progression of scotomas in glaucoma. Am J Ophthalmol 1986;101:1-6.

16 General household survey: analysis of ophthalmic data 1990-91 to 1993-94. London: Government Statistical Service, July 1995.

17 Schwartz B, McCarty G, Rosner B. Increased plasma free cortisol in ocular hypertension and open angle glaucoma. Arch Ophthalmol 1987:105:1060-5.

18 Brunner EJ, Marmot MG. Social organisation, stress and health. In: Marmot MG, Wilkinson RG, eds. Social determinants of health. Oxford: Oxford University Press, 1999.

19 Davey Smith G, Phillips AN. Confounding in epidemiological studies: why "independent" effects may not be all they seem. BMJ 1992;305:757-9.

20 Stallone DD, Brunner EJ, Marmot MG, Bingham SA. Dietary assessment in Whitehall II: the influence of reporting bias on apparent socioeconomic variation in nutrient intakes. Eur J Clin Nutr 1997;51: $815-25$
21 Tielsch JM, Sommer A, Katz J, Quigley H, Ezrine S. Socioeconomic status and visual impairment among urban Americans. Arch Ophthalmo 1991;109:638-41.

22 Quigley H, West S, Rodriguez J, Munoz B, Klein R, Snyder R. Prevalence of glaucoma in a population-based study of Hispanics. ARVO abstract 2896; March 2000.

23 Smith LK, Thompson JR, Woodruff G, Hiscox F. Social deprivation and age at presentation in amblyopia. J Public Health Med 1994;16:348-51.

24 Calle EE, Flanders WD, Thun MJ, Martin LM. Demographic predictors of mammography and Pap smear screening in US women. Am J Public Health 1993:83:53-60.

25 Wells BL, Horm JW. Stage at diagnosis in breast cancer: race and socioeconomic factors. Am J Public Health 1992;82:1383-5.

26 Powe BD. Fatalism amongst elderly African-Americans. Effects on colorectal cancer screening. Cancer Nursing 1995;18:385-92.

27 Robinson JK, Altman JS, Rademaker AW. Socioeconomic status and attitudes of 51 patients with giant basal and squamous cell carcinoma and paired controls. Arch Dermatol 1995;131:428-31.

28 Wormald RPL, Rauf A. Glaucoma screening. J Med Screen 1995;2:109-14

29 Griffiths PG. A surfeit of screening? BMJ 1997;315:318.

30 Report of the independent inquiry into inequalities in health. London: Stationery Office, 1998 (Acheson report).

(Accepted 14 December 2000

\title{
Duration of breast feeding and arterial distensibility in early adult life: population based study
}

\author{
C P M Leeson, M Kattenhorn, J E Deanfield, A Lucas
}

\begin{abstract}
Objectives To test the hypothesis that duration of breast feeding is related to changes in vascular function relevant to the development of cardiovascular disease.

Design Population based observational study. Setting Cambridge.

Participants 331 adults (171 women, 160 men) aged between 20 and 28 years, born in Cambridge

Maternity Hospital.

Main outcome measures Distensibility of brachial artery, type and duration of infant feeding, current lipid profile, and other cardiovascular risk factors. Results The longer the period of breast feeding the less distensible the artery wall in early adult life, with no sex differences (regression coefficient $=-3.93$ $\mu \mathrm{m} / \mathrm{month}, 95 \%$ confidence interval -7.29 to -0.57 , $\mathrm{P}=0.02)$. However, in those breast fed for less than four months, arterial distensibility was not significantly reduced compared with an exclusively formula fed group. The vascular changes observed were not explained by alterations in plasma cholesterol concentration in adult life.

Conclusions Breast feeding in infancy is related to reduced arterial function 20 years later. These data should not alter current recommendations in favour of breast feeding, which has several benefits for infant health. Further work is needed, however, to explore the optimal duration of breast feeding in relation to cardiovascular outcomes.
\end{abstract}

\section{Introduction}

Nutrition in early postnatal life may have major, long term "programming" effects on the physiology, metabolism, and clinical outcome of animals and humans. ${ }^{1-3}$ Coronary artery disease is one outcome in humans linked to early growth and nutrition. Although breast feeding has been associated with a lower risk of cardiovascular disease, men born earlier this century who had still been breast fed aged 1 year had higher rates of ischaemic heart disease $60-70$ years later compared with the expected rate for men of that age. ${ }^{2}$ If this observation were causal, it would raise an important question about the optimal duration of breast feeding.

Although observational evidence linking early nutrition to later cardiovascular disease might be subject to confounding, experimental evidence also exists linking atherosclerosis and breast feeding in non-human primates. Studies in baboons that were breast fed or formula fed throughout infancy and then placed on a Western style diet, high in saturated fats, showed that those previously breast fed had an abnormal lipid profile and more arterial fatty streaks in adulthood. ${ }^{1}$ One hypothesis was that breast feeding programmed baboons to be conservative with cholesterol-perhaps appropriately for their natural diet-but when they consumed a Western diet this programming led to arterial disease. Were these findings supported in humans, it would have implications for infants weaned on to a Western diet.

We studied a UK population to test further the hypothesis that duration of breast feeding might influence later emergence of vascular disease. To minimise potential influences of other lifestyle factors throughout adulthood we studied a young cohort. This was feasible because early pathophysiological changes in the artery, relevant to the development of atherosclerosis, can now be measured early in life with non-invasive imaging techniques. ${ }^{45}$ Our group has already shown links between vascular dysfunction and growth and nutrition during childhood. ${ }^{67}$ In this study, we
Editorial by Booth

Medical Research Council Childhood Nutrition Research Centre, Institute of Child Health,

London

WC1N 1EH

C P M Leeson research fellow

A Lucas professor

Vascular Physiology Unit, Great Ormond Street Hospital for Children, London WC1N 3JH

M Kattenhorn vascular technician J E Deanfield professor

Correspondence to: C P M Leeson cpm_leeson@ hotmail.com

BMJ 2001;322:643-7 
measured arterial distensibility, a measure of vessel wall stiffness, in a large cohort of adults in their 20s and related it to duration of breast feeding.

\section{Participants and methods}

\section{Study design}

We studied 331 subjects (160 men; 171 women) aged 20 to 28 years born in Cambridge Maternity Hospital. We invited random samples of those born between 1969 and 1975 to attend a clinic for evaluation of cardiovascular risk profile by venepuncture, questionnaire, physical measurements, and vascular studies. Invitations were sent until the planned sample size was reached. Ethical approval and informed consent were obtained. To determine possible biases in the study sample, we compared the distribution of risk factors in this group to that in the United Kingdom and to data obtained in our questionnaire from a subgroup of people who initially declined to participate.

\section{Measurement of cardiovascular risk factors}

We analysed a fasting venous blood sample for insulin, glucose, and lipid profile using routine methods. Weight, height, blood pressure, and smoking history were recorded. We assessed social influences by attained education level and socioeconomic groupings. ${ }^{8}$ Before attending, participants collected information from their mothers on how they had been fed as an infant. We grouped them as either only bottle fed or having received breast milk. For those who had been breast fed, we recorded how long breast feeding had continued. ${ }^{9}$

\section{Vascular study measurements}

Distension of the brachial artery during the cardiac cycle was measured as described previously. ${ }^{710}$ Briefly, the artery was imaged with an Acuson 128XP/10 and movement of the arterial walls recorded with an auto- mated wall tracking system (Ingenious Medical Systems, Arnhem, Netherlands). By relating change in diameter over the cardiac cycle to pulse pressure, "stiffness" of the vessel wall can be quantified.

\section{Statistical analysis}

We assessed continuous relations between explanatory variables and arterial distensibility using multiple regression. Variables were related to absolute distension with pulse pressure, age, sex, and vessel size as independent variables. ${ }^{7}$ Further models examined adjustment for other factors. To investigate the effect of duration of breast feeding further, the group was dichotomised around the median duration of breast feeding. We then assessed differences between these divisions, as well as other groups (such as breast fed compared with bottle fed), using $t$ tests. Distensibility was represented as a coefficient (change in arterial cross sectional area between diastole and systole relative to the area at diastole, divided by pulse pressure). ${ }^{57}$

\section{Results}

We sent invitations to 1526 people, of whom 420 (28\%) agreed to participate, 229 (15\%) declined, and 877 $(57 \%)$ did not reply. In all, 344 (23\%) subjects were able to attend for vascular investigations. Full details of vascular function, risk factors, and infant feeding practice were available for $331(96 \%)$ of these (table 1). The study group had similar body size, body mass index, blood pressure, and smoking rates to young adults generally in the United Kingdom. ${ }^{11}$

\section{Arterial distensibility}

The distensibility coefficient was $0.129 \mathrm{~mm} \mathrm{Hg}^{-1}$ in men and $0.145 \mathrm{~mm} \mathrm{Hg}^{-1}$ in women (95\% confidence interval for difference -0.032 to $-0.002, \mathrm{P}=0.04)$. There was

Table 1 Main characteristics of study population. Values are mean (SD or range) unless stated otherwise

\begin{tabular}{|c|c|c|c|c|}
\hline Variable & Breast fed & Bottle fed & $\begin{array}{l}P \text { value for difference } \\
\text { between groups }\end{array}$ & $\begin{array}{l}\text { Participants who only } \\
\text { completed questionnaire* }\end{array}$ \\
\hline Age (years) & 23 (20 to 28$)$ & 23 (20 to 27$)$ & 0.07 & 23 (21 to 27 ) \\
\hline Weight (kg) & $70.4(14.5)$ & $68.7(13.1)$ & 0.28 & $68.3(17)$ \\
\hline Body mass index $\left(\mathrm{kg} / \mathrm{m}^{2}\right)$ & $24.2(4.1)$ & $24.3(3.7)$ & 0.83 & $26.8(6.3)$ \\
\hline Length of breast feeding (months) & $3.33(0$ to 18$)$ & - & - & - \\
\hline Distensibility coefficient $\left(\mathrm{mm} \mathrm{Hg}^{-1}\right)$ & $0.133(0.07)$ & $0.140(0.08)$ & 0.38 & - \\
\hline Cholesterol (mmol/l) & $4.43(0.99)$ & $4.61(1.01)$ & 0.11 & - \\
\hline LDL cholesterol (mmol/l) & $2.71(0.88)$ & $2.90(0.93)$ & 0.07 & - \\
\hline HDL cholesterol $(\mathrm{mmol} / \mathrm{l})$ & $1.18(0.25)$ & $1.18(0.31)$ & 0.96 & - \\
\hline Systolic blood pressure $(\mathrm{mm} \mathrm{Hg})$ & $128(14)$ & $128(14)$ & 0.93 & - \\
\hline Non-smokers & $75(50)$ & $96(53)$ & 0.78 & $31(56)$ \\
\hline \multicolumn{5}{|l|}{ No (\%) in social class: } \\
\hline I & $12(8)$ & $13(7)$ & \multirow{6}{*}{0.19} & - \\
\hline II & $36(24)$ & $33(18)$ & & - \\
\hline IIINM & $51(34)$ & $62(34)$ & & - \\
\hline IIIM & $24(16)$ & $36(20)$ & & - \\
\hline IV & 22 (15) & $33(18)$ & & - \\
\hline V & $4(3)$ & $5(3)$ & & - \\
\hline
\end{tabular}

$\mathrm{LDL}=$ low density lipoprotein, $\mathrm{HDL}=$ high density lipoprotein. *Data presented for comparison. 
no variation with age (regression coefficient $=-1.6$, $95 \%$ confidence interval -4.9 to $1.8, \mathrm{P}=0.36$ ). As expected, reduced distensibility was related to increased total serum cholesterol concentration and systolic blood pressure (table 2). ${ }^{7}$ Social class and smoking were unrelated to arterial function. Arterial distensibility was not related to birthweight or weight in infancy.

There was an inverse relation between duration of breast feeding and arterial distensibility (regression coefficient $=-3.93 \mu \mathrm{m} / \mathrm{month}, 95 \%$ confidence interval -7.29 to $-0.57, \mathrm{P}=0.02$ ) (figure). The regression coefficient was negative in men $(-2.9)$ and women ( -4.3$)$ analysed separately, although because of reduced sample size the result was significant only in women. There was no interaction between sex and duration of breast feeding, and we therefore conducted further analyses on the combined cohort. Participants who had been exclusively breast fed for less than four months had similar distensibility to those who had never been breast fed (distensibility in bottle fed $=0.1388 \mathrm{~mm}$ $\mathrm{Hg}^{-1}$ and breast fed less than four months $=0.1457 \mathrm{~mm}$ $\mathrm{Hg}^{-1}$, mean difference $=0.007 \mathrm{~mm} \mathrm{Hg}^{-1}, 95 \%$ confidence interval -0.026 to $0.012, \mathrm{P}=0.46$ ). Those who had been breast fed for four months or more had significantly lower distensibility than those who had been breast fed for less than four months (distensibility for those breast fed for four months or more $=0.1200 \mathrm{~mm} \mathrm{Hg}^{-1}$ mean difference from those breast fed for less than four months $=-0.026 \mathrm{~mm} \mathrm{Hg}^{-1}, \quad-0.038$ to -0.048 , $\mathrm{P}=0.02)$.

\section{Relation of duration of breast feeding to} cardiovascular risk factors and other variables

Duration of breast feeding was unrelated to lipid profile, body size, body mass index, smoking patterns, blood pressure, social class, birthweight, or prevalence of premature cardiovascular disease in relatives (regression coefficient between duration of breast feeding and cholesterol concentration $=-0.16$ months $/ \mathrm{mmol} / 1,95 \%$ confidence interval -0.49 to $0.17, \mathrm{P}=0.4$ ). The strength of the association between duration of breast feeding and distensibility was unaffected by inclusion of current lipid profile, body mass index, height, weight, or social class in the regression model (table 3 ).

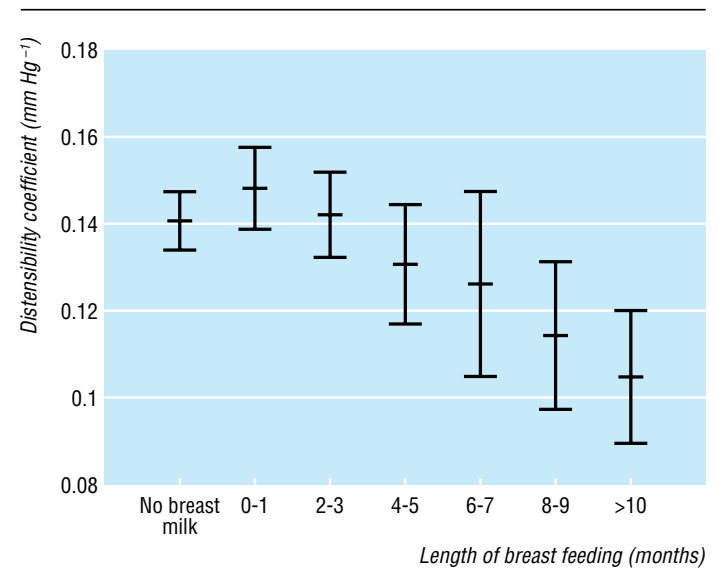

Mean (SE) distensibility coefficient for brachial artery in relation to duration of breast feeding
Table 2 Linear regression coefficients for associations between main variables and arterial distension (with pulse pressure, age, sex, and resting vessel size included in model). Units are $\mu \mathrm{m}$ per unit change in explanatory variable

\begin{tabular}{lcc} 
Variable & Regression coefficient $\mathbf{( 9 5 \%} \mathbf{~ C l )}$ & P value \\
\hline Total cholesterol $(\mathrm{mmol} / \mathrm{l})$ & $-8.5(-14.5$ to -2.5$)$ & 0.005 \\
\hline LDL cholesterol $(\mathrm{mmol} / \mathrm{l})$ & $-8.8(-15.6$ to -1.9$)$ & 0.01 \\
\hline Body mass index $\left(\mathrm{kg} / \mathrm{m}^{2}\right)$ & $-21.1(-36.5$ to 5.8$)$ & 0.007 \\
\hline Diastolic blood pressure $(\mathrm{mm} \mathrm{Hg})$ & $-1.92(-2.68$ to -1.16$)$ & $<0.001$ \\
\hline Social class & $-0.1(-0.84$ to 0.60$)$ & 0.75 \\
\hline
\end{tabular}

Table 3 Linear regression coefficients for relation between length of breast feeding and distensibility with adjustments for pulse pressure, age, sex, and resting vessel plus cholesterol concentration, body mass index, and socioeconomic factors

\begin{tabular}{lcc} 
Variable & Regression coefficient $\mathbf{( 9 5 \%} \mathbf{C I})(\boldsymbol{\mu m} / \mathbf{m o n t h})$ & $\mathbf{P}$ value \\
\hline Length of breast feeding & $-3.9(-7.3$ to -0.6$)$ & 0.02 \\
\hline+ Total cholesterol & $-3.8(-7.2$ to -0.4$)$ & 0.03 \\
\hline+ Body mass index & $-3.9(-7.2$ to -0.5$)$ & 0.02 \\
\hline+ Social class & $-3.9(-7.3$ to -0.6$)$ & 0.02 \\
\hline
\end{tabular}

\section{Discussion}

We found that distensibility of the brachial artery in young adults was related to the duration of breast feeding in infancy. Longer duration of breast feeding was associated with stiffer arteries. As we studied young adults, our results are less likely to be confounded by the effects of other cardiovascular risk factors that are present in older cohorts. The results suggest that the effect of breast feeding on cardiovascular risk occurs early in life.

\section{Possible explanations for the effect}

Breast feeding evolved in mammals over millions of years and is generally considered optimal for humans. The commonly cited advantages over formula feeding include reduced infection and atopy and increased cognitive development. ${ }^{12}$ The optimal duration of breast feeding remains inadequately researched. We found an apparent adverse outcome in people who had had prolonged breast feeding. This finding is consistent with the results of an observational study in which men who had been breast fed at 1 year had an increased risk of ischaemic heart disease 60 years later. ${ }^{2}$ This finding was suggested to be due to programming of cholesterol metabolism in response to the unique lipid or hormone contents of breast milk. These factors might alter expression of hepatic enzymes or low density lipoprotein receptors, changing the response to a high fat diet later in life. ${ }^{13-16}$ This hypothesis is consistent with the experimental studies in primates, where breastfed baboons given a Western style high saturated fat diet had more early atherosclerotic changes in adulthood than formula fed animals.

In our study, however, longer duration of breast feeding was not associated with significantly higher total cholesterol or lipoprotein concentration in adulthood. Furthermore, models relating breast feeding to distensibility were not affected by inclusion of current lipid profile. Thus our results do not support a hypothesis of deranged blood lipid profiles in adulthood.

An alternative hypothesis would be that breast feeding influences lipid metabolism much earlier, during the infant feeding period, resulting in early formation of arterial fatty streaks. Animal studies show arterial elasticity is reduced during fatty streak 
formation in infancy before other pathophysiological changes. ${ }^{17}$ Cholesterol is laid down in the vessel wall from the first months, with a peak prevalence of fatty streaks during the first year ${ }^{18}$ when cholesterol concentrations are higher in breastfed infants. ${ }^{190}$ If breast feeding is extended throughout infancy, the vessel wall is exposed to raised circulating cholesterol concentrations for longer. Most arterial lesions seem to regress initially, but in the primate studies above, animals breast fed as infants and then placed on a high saturated fat diet had more fatty streaks in adulthood. ${ }^{1}$ In humans, such early arterial changes might persist into later life if subsequent diet interferes with their natural regression. A small, inconclusive postmortem study of adolescents showed more arterial lesions in those who had been breast fed, further supporting an early effect of breast feeding. ${ }^{21}$ More work is needed to investigate dietary differences in vascular lipid deposition in early life.

\section{Relevance of arterial distensibility}

Arterial distensibility is known to diminish with age in relation to cardiovascular risk factors and is reduced in subjects with frank coronary disease. ${ }^{22}{ }^{23}$ Indeed, the potential impact of such risk factors is apparent in this study, which showed reduced arterial distensibility in young adults with higher blood pressure, cholesterol, or body mass index. Although further investigation is needed, it seems likely that arterial distensibility is related to risk of vascular disease.

There was no direct record of feeding method or duration. We used maternal recall, which has been independently validated for collecting such data ${ }^{9}$ and provides reproducible data 30 or more years after birth. ${ }^{24}$ Further early dietary information was limited as the study was retrospective. Prospective investigations could take account of age of weaning and subsequent diet as well as the more recent secular changes in infant feeding, notably duration of use and design of infant formula.

Comparison of the relative influence of risk factors on arterial distensibility suggests that breast feeding has an important effect. Extending breast feeding by two months has an effect on arterial distensibility that is broadly equivalent to that produced by a $1 \mathrm{mmol} / \mathrm{l}$ rise in cholesterol or $4 \mathrm{~mm} \mathrm{Hg}$ increase in blood pressure. Although the effect is apparently larger in women, there was no significant difference between sexes. This may be because the underlying arterial changes were established before development of the hormonal protection that reduces the incidence of coronary disease in women during reproductive life.

\section{Implications}

We emphasise that our observational data do not establish a causal relation between length of breast feeding and cardiovascular disease. Nevertheless, our findings are supported by previous human and experimental animal data. ${ }^{12}$ We tried to minimise confounding by studying a young cohort and adjusted for potential influences on distensibility that might also relate to duration of breast feeding. Further confounding should be explored in future studies.

Since breast feeding is widely accepted and promoted as the best nutrition for infants, any suggestion of an association between duration of breast feed-

\section{What is already known on this topic}

No data exist on the optimal duration of breast feeding

One study found that men who had been breast fed at 1 year had higher rates of ischaemic heart disease

\section{What this study adds}

Arterial distensibility (a marker of early cardiovascular disease) in adults aged 20-28 decreased with increasing duration of breast feeding

No difference in distensibility was found between participants who had been bottle fed and those breast fed for less than four months

Duration of breast feeding was not related to cholesterol concentration in adulthood

Any effect of breast feeding on cardiovascular risk probably occurs in infancy

ing and vascular health requires careful and critical examination. We took full account of the feeding period and showed a graded relation between length of breast feeding and the decline in distensibility. However, arterial distensibility was similar in those breast fed for up to four months to that in participants who were not breast fed.

At this stage our findings should not influence current advice on the importance of breast feeding. Even if prolonged breast feeding were confirmed to have disadvantages, these would need to be carefully weighed against the advantages. For example, in developing countries the benefit of prolonged breast feeding in infants and toddlers would be an overriding consideration. Nevertheless, there is an urgent public health need to study further the possible influence of a longer period of breast feeding on the evolution of arterial disease.

We thank Ian Merryweather, Sarah Jones, and Tristan Cope for help with data collection and laboratory analysis and Dr David Muller for coordinating the biochemical work.

Contributors: CPML and AL designed the study, analysed and interpreted the data, and wrote the paper. MK and JED contributed to the design of the study and revision of the paper. CPML and MK managed the study and data collection. CPML and AL will act as guarantors.

Funding: The work was funded by the Medical Research Council. All work in the Institute of Child Health and Great Ormond Street Hospital also benefits from NHS research and development funding.

Competing interests: The centre has collaborated with the infant food industry for its outcome studies on nutrition.

1 Mott GE, Lewis DS, McGill HC. Programming of cholesterol metabolism by breast and formula feeding. In: Ciba Foundation symposium. The childhood environment and adult disease: Chichester: Wiley, 1991:128-74.

2 Fall CH, Barker DJP, Osmond C, Winter PD, Clark PM, Hales CN Relation of infant feeding to adult serum cholesterol concentration and death from ischaemic heart disease. BMJ 1992;304:801-5.

3 Lucas A. Programming by early nutrition in man. In: Ciba Foundation symposium. The childhood enviromment and adult disease. Chichester: Wiley, 1991:38-55.

4 Celermajer DS, Sorenson KE, Gooch VM, Spiegelhalter DJ, Miller OT, Sullivan I, Deanfield JE. Non-invasive detection of endothelial dysfunction in children and adults at risk of atherosclerosis. Lancet 1992;340:1111-5. 
5 Hoeks APG, Brands PJ, Smeets FAM, Reneman RS. Assessment of the distensibility of superficial arteries. Ultrasound Med Biol 1990;16:121-8.

6 Leeson CPM, Whincup PH, Cook DG, Donald AE, Papacosta O, Lucas A et al. Flow mediated dilation in 9-11 year old children: the influence of childhood and intrauterine factors. Circulation 1997;96:2233-8.

7 Leeson CPM, Whincup PH, Cook DG, Mullen MJ, Donald AE, Seymour $\mathrm{CA}$, et al. Cholesterol and arterial distensibility in the first decade of life: a population-based study. Circulation 2000;101:1533-8.

Office of Population Censuses and Surveys. Occupational mortality decennial supplement 1979-80;1982-83. London: HMSO, 1986.

9 Kark JD, Troya G, Friedlander Y, Slater PE, Stein Y. Validity of maternal reporting of breast feeding history and the association with blood lipids in 17 year olds in Jerusalem. J Epidemiol Community Health 1984;38:21825.

10 Leeson CPM, Thorne S, Donald AE, Mullen MJ, Clarkson P, Deanfield JE Non-invasive measurement of endothelial function: effect on brachial artery dilation of graded endothelial dependent and independent stimuli. Heart 1997;78:22-7.

11 Office of Population Censuses and Surveys. Health survey of England 1995 London: HMSO, 1997.

12 American Academy of Pediatrics. Breast feeding and the use of human milk. Pediatrics 1997;100:1035-9.

13 Phillips DI, Barker DJP, Osmond C. Infant feeding, fetal growth and adult thyroid function. Acta Endocrinol Copenh 1993;129:134-8.

14 Mott GE, Jackson EM, DeLallo L, Lewis DS, McMahan CA. Differences in cholesterol metabolism in juvenile baboons are programmed by breast versus formula feeding. J Lipid Res 1995;36:299-307.

15 Wong WW, Hachey DL, Insull W, Opekun AR, Klein PD. Effect of dietary cholesterol on cholesterol synthesis in breast fed and formula fed infants. J Lipid Res 1993;34:1403-11.
16 Mott GE, DeLallo L, Driscoll DM, McMahan CA, Lewis DS. Influence of breast and formula feeding on hepatic concentrations of apolipoprotein and low density lipoprotein receptor mRNAs. Biochem Biophys Acta 1993;1169:59-65.

17 Hironaka K, Yano M, Kohno M, Tanigawa T, Obayashi M, Konishi M, et al. In vivo aortic wall characteristics at the early stage of atherosclerosis in rabbits. Am J Physiol 1997;273:H1142-7.

18 Stary HC. Evolution and progression of atherosclerotic lesions in coronary arteries in children and young adults. Arteriosclerosis 1989;99(suppl I): I 19-39.

19 Friedman G, Goldberg SJ. Concurrent and subsequent serum cholesterol of breast and formula fed infants. Am J Clin Nutr 1975;281:42-5.

20 Akeson PM, Axelsson IE, Raiha NC. Plasma lipids and apolipoproteins in breast-fed and formula-fed Swedish infants. Acta Paediatr 1999;881:1-6.

21 Burr ML, Beasley WH, Fisher CB. Breast feeding, maternal smoking and early atheroma. Eur Heart J 1984;5:588-91.

22 Benetos A, Laurent S, Hoeks APG, Bontonyrie PH, Safar ME. Arterial alterations with ageing and high blood pressure. Arterioscler Thromb 1993;13:90-7.

23 Dart AM, Lacombe F, Yeoh JK, Cameron JD, Jennings GL, Laufer E, et al. Aortic distensibility in patients with isolated hypercholesterolaemia, coronary artery disease or cardiac transplant. Lancet 1991;338:696-7.

24 Tomeo CA, Rich-Edwards JW, Michels KB, Berkey CS, Hunter DJ, Frazier AL, et al. Reproducibility and validity of maternal recall of pregnancy-related events. Epidemiology 1999;10:774-7.

\section{Employment status and health after privatisation in white collar civil servants: prospective cohort study}

Jane E Ferrie, Pekka Martikainen, Martin J Shipley, Michael G Marmot, Stephen A Stansfeld, George Davey Smith

\begin{abstract}
Objectives To determine whether employment status after job loss due to privatisation influences health and use of health services and whether financial strain, psychosocial measures, or health related behaviours can explain any findings.

Design Data collected before and 18 months after privatisation.

Setting One department of the civil service that was sold to the private sector.

Participants 666 employees during baseline screening in the department to be privatised. Main outcome measures Health and health service outcomes associated with insecure re-employment, permanent exit from paid employment, and unemployment after privatisation compared with outcomes associated with secure re-employment. Results Insecure re-employment and unemployment were associated with relative increases in minor psychiatric morbidity (mean difference 1.56 (95\% confidence intervals interval 1.0 to 2.2$)$ and 1.25 (0.6 to 2.0) respectively) and having four or more consultations with a general practitioner in the past year (odds ratio 2.04 (1.1 to 3.8) and 2.39 (1.2 to 4.7) respectively). Health outcomes for respondents permanently out of paid employment closely resembled those in secure re-employment, except for a substantial relative increase in longstanding illness (2.25; 1.1 to 4.4$)$. Financial strain and change in psychosocial measures and health related behaviours accounted for little of the observed associations. Adjustment for change in minor psychiatric morbidity attenuated the association between insecure
\end{abstract}

re-employment or unemployment and general practitioner consultations by $26 \%$ and $27 \%$, respectively.

Conclusions Insecure re-employment and unemployment after privatisation result in increases in minor psychiatric morbidity and consultations with a general practitioner, which are possibly due to the increased minor psychiatric morbidity.

\section{Introduction}

Traditionally the public sector in the United Kingdom was immune to the pressures of the marketplace, and among its main attractions were job security, a career, and good conditions of service. The future privatisation of the executive functions of government came on to the agenda with the introduction of the "Next Steps" programme in August 1988. Early in the restructuring, one of the 20 departments participating in the Whitehall II study, the Property Services Agency, was sold to the private sector.

Rumours of the forthcoming privatisation reached the work force two to three years before the sale, and during this "anticipation" phase there was a deterioration in self reported health. ${ }^{1}$ During the three months before the sale, both self reported morbidity and physiological risk factors had increased relative to what was reported by respondents in the control departments. ${ }^{2}$

We examined the effects on health and general practitioner consultations of employment status 18 months after the privatisation and whether any associations could be explained by changes in financial strain, psychosocial measures, and health related behaviours.
Centre for Health and Society, Department of Epidemiology and Public Health, University College London Medical School, London WC1E 6BT

Jane E Ferrie senior research fellow Martin J Shipley senior lecturer in medical statistic Michael G Marmot director

continued over

BMJ 2001;322:647-51

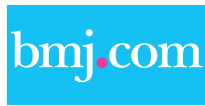

The full version of this paper appears on the BMJ's

website. This article is part of the BMJ's trial of open peer review, and documentation relating to this also appears on the website 